\title{
Deceased Donation Uterus Transplantation: A Review
}

\author{
Natasha Hammond-Browning ${ }^{1, *}$ (i) and Si Liang Yao ${ }^{2}$ \\ 1 School of Law and Politics, Cardiff University, Law Building, Museum Avenue, Cardiff CF10 3AX, UK \\ 2 School of Medicine, Cardiff University, UHW Main Building, Heath Park, Cardiff CF14 4XN, UK; \\ YaoSL@cardiff.ac.uk \\ * Correspondence: Hammond-BrowningN@Cardiff.ac.uk
}

Citation: Hammond-Browning, N.; Yao, S.L. Deceased Donation Uterus Transplantation: A Review. Transplantology 2021, 2, 140-148. https://doi.org/10.3390/ transplantology2020014

Academic Editor: Iori Kisu

Received: 26 February 2021

Accepted: 20 April 2021

Published: 28 April 2021

Publisher's Note: MDPI stays neutral with regard to jurisdictional claims in published maps and institutional affiliations.

Copyright: (C) 2021 by the authors Licensee MDPI, Basel, Switzerland. This article is an open access article distributed under the terms and conditions of the Creative Commons Attribution (CC BY) license (https:/ / creativecommons.org/licenses/by/ $4.0 /)$.

\begin{abstract}
Uterus transplantation (UTx) offers women with absolute uterine factor infertility the option to gestate and birth their own biologically related child. The first birth following living donation UTx happened in 2014. The first birth following deceased donation happened in December 2017, with further successes since. Interest in deceased donation UTx is increasing. The authors established a database to track UTx clinical trials and outcomes. Utilising this database and existing literature, this article reviews the first reported cases of deceased donation UTx and outcomes, and drawing upon comparisons with living donor UTx, comments upon the future for this area of reproductive transplantation research. This is the first article to bring together the literature on deceased donation UTx procedures and outcomes.
\end{abstract}

Keywords: uterus transplantation; deceased donors; procedures; births; outcomes; lessons; registry

\section{Introduction}

The reproductive options for women with absolute uterine factor infertility (AUFI) are surrogacy or adoption, availability of which is highly dependent upon the legal jurisdiction within which women reside. Even where legally accessible, women with AUFI may be unwilling or unable to access surrogacy or adoption due to financial reasons and/or religious, ethical, social, or personal objections. However, since 2014, women with AUFI have been presented with the possibility of gestating their own biological child following a uterus transplant. Uterus transplantation (UTx) is a developing technique, still in its research infancy, and is heralded as a way of increasing the reproductive autonomy of women with AUFI.

The concept of UTx has been around for many years, with the earliest successful attempt being in a dog in the 1960s [1]. Sixty years on, more than 70 attempts at human UTx have taken place, resulting in $\geq 24$ live births across 11 countries [2]. Notable milestones include the first human UTx in Saudi Arabia in 2000 [3], the first birth following a living donor (LD) transplant in Sweden in 2014 [4], and the first birth following a deceased donor (DD) transplant in Brazil in 2017 [5].

Five births following DD UTx have been reported in the literature. These took place in Brazil; Cleveland, USA; Dallas, USA; the Czech Republic; and Pennsylvania, USA [5-8]. While an International Registry for Uterus Transplantation (IRUTx) has been established [9], it is increasingly apparent that there is a strong need for publication of public-facing reports that collate and report uterus transplants and outcomes [10], as further procedures and livebirths have been reported in the media but have not yet been reported in peer reviewed publications (including Belgium, Sweden and Turkey).

The benefits and disadvantages of living and deceased donation have been heavily debated in the literature surrounding UTx [11,12]. Although the ability to extensively evaluate the living donor's obstetric and family history before selection is a major advantage, as well as the ability to electively plan the surgery $[6,13]$, there are drawbacks to LD UTx. The most significant are the risks of both physical and psychological harm to the donor 
herself. It has been reported that $\geq 12 \%$ of LD have suffered major complications which include bleeding, infection, injury to ureters and ovarian dysfunction $[14,15]$. These may prove unacceptable to a potential LD considering undergoing a non-therapeutic surgery, and requires full disclosure of the risks in order that the LD can give informed consent to the procedure [12]. It should be noted that some UTx procedures have utilised nondirected altruistic living donors, for whom the risk has been deemed acceptable despite no therapeutic benefit to themselves. Additionally, where living related donors are used, donors and recipients may have concerns about family dynamics and experience both internal and external pressures to give or take the uterus [16]. Recipients may therefore prefer DD UTx in order to avoid/reduce these concerns. Surgically, deceased donations can be advantageous as they allow the retrieval of longer vascular grafts, reducing the risk of thrombosis and subsequent transplant failure in the recipient [17]. Alongside the medical experiences of $\mathrm{LD}$ versus DD, it is important to recognise the vital role that ethics also has to play in this debate. Balancing concerns regarding consent, voluntariness, harms and risks to living donors may lead to the conclusion that $\mathrm{DD}$ is ethically preferred to LD, although the imposition of harm upon LD may be justified in research and organ transplantation contexts, thereby not prohibiting LD UTx [11]. The advantages and disadvantages of LD and DD UTx are summarised in Table 1.

Since the proof of concept of DD UTx in 2017, UTx procedures utilising deceased donors have steadily increased in number, and trials are now being conducted in several countries (Table 2). While the number of LD UTx procedures is significantly higher than DD UTx, the importance of conducting DD UTx trials should not be underestimated. Considering that the first LD UTx have already been reviewed [18,19], this article brings together the published literature on DD UTx, reviews the progress of DD UTx, the outcomes, lessons learnt, and the future for this area of research.

Table 1. Advantages and disadvantages of living donor (LD) and deceased donor (DD) uterus transplantation.

\begin{tabular}{|c|c|c|}
\hline & Advantages & Disadvantages \\
\hline LD & $\begin{array}{l}\text { - } \quad \text { Extensively evaluate obstetric, medical and family } \\
\text { history } \\
\text { - } \quad \text { Extensive testing pre-transplant } \\
\text { - } \quad \text { Clectively plan surgery for donor and recipient } \\
\text { - } \quad \text { Donor, sense of satisfaction through helping others }\end{array}$ & 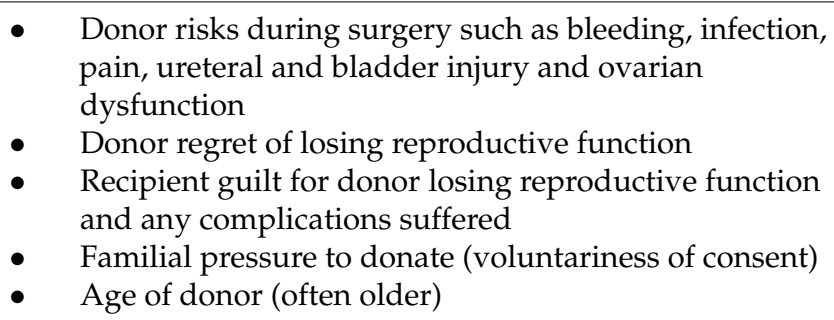 \\
\hline DD & $\begin{array}{l}\text { - } \\
\text { - } \quad \text { Ubility to harvest longer vascular grafts which } \\
\text { Using bladder peritoneum allows better graft } \\
\text { support [20] } \\
\text { - } \quad \text { Longer vaginal cuff for better vaginal-vaginal } \\
\text { anastomosis [17] } \\
\text { - } \text { Anonymity of donation } \\
\text { - } \quad \text { Recipient, less feeling of 'debt' to the donor } \\
\text { - No emotional guilt } \\
\text { - No regret } \\
\text { - No harm to donor }\end{array}$ & $\begin{array}{l}\text { - Need ask family for donation and obtain obstetric } \\
\text { history at time of death, which can be difficult } \\
\text { - } \quad \text { Shortage of deceased donors (DD) } \\
\text { At the moment, DD UTx can have a longer cold } \\
\text { ischaemic time (CIT) than LD, which could affect } \\
\text { viability and functionality of graft }[5,8] \\
\text { - Short time frame, inability to plan surgeries and } \\
\text { extensively test donor }\end{array}$ \\
\hline
\end{tabular}


Table 2. Order of deceased donor transplants and outcomes as published in the literature as of 31st January 2021.

\begin{tabular}{|c|c|c|c|c|}
\hline Order & Country & Year of UTx & Outcome & Where Reported \\
\hline 1 & Turkey & 2011 & In situ & $\begin{array}{l}\text { Uterus transplantation from a deceased donor. } \\
\text { Ozkan O, Akar ME, Erdogan O, Ozkan O, Hadimioglu N. Fertil Steril. } 2013 \\
\text { December;100(6):e41. doi:10.1016/j.fertnstert.2013.06.041. }\end{array}$ \\
\hline 2 & $\begin{array}{c}\text { USA } \\
\text { (Cleveland) }\end{array}$ & 2016 & $\begin{array}{l}\text { Hysterectomy day } 12 \\
\text { (Vascular candidal } \\
\text { infection) }\end{array}$ & $\begin{array}{l}\text { Deceased donor uterine transplantation. } \\
\text { Flyckt R, Kotlyar A, Arian S, Eghtesad B, Falcone T, Tzakis A. Fertil Steril. } \\
2017 \text { March;107(3):e13. doi:10.1016/j.fertnstert.2016.12.009. }\end{array}$ \\
\hline 3 & $\begin{array}{l}\text { USA } \\
\text { (Baylor) }\end{array}$ & 2016 & $\begin{array}{l}\text { Birth 2020. Caesarean } \\
\text { hysterectomy }\end{array}$ & $\begin{array}{l}\text { Twelve Live Births After Uterus Transplantation in the Dallas UtErus Transplant } \\
\text { Study. } \\
\text { Johannesson L, Testa G, Putman JM, McKenna GJ, Koon EC, York JR, Bayer J, } \\
\text { Zhang L, Rubeo ZS, Gunby RT, Gregg AR. Obstet Gynecol. } 2021 \text { February } \\
\text { 1;137(2):241-249. doi:10.1097/AOG.0000000000004244.PMID: } 33416285 .\end{array}$ \\
\hline 4 & $\begin{array}{l}\text { Czech } \\
\text { Republic }\end{array}$ & 2016 & $\begin{array}{l}\text { Hysterectomy day } \\
\text { 7—-thrombosis }\end{array}$ & $\begin{array}{l}\text { Revaluation and lessons learned from the first } 9 \text { cases of a Czech uterus } \\
\text { transplantation trial: Four deceased donor and } 5 \text { living donor uterus } \\
\text { transplantations. } \\
\text { Chmel R, Novackova M, Janousek L, Matecha J, Pastor Z, Maluskova J, } \\
\text { Cekal M, Kristek J, Olausson M, Fronek J. Am J Transplant. } 2019 \\
\text { March;19(3):855-864. doi:10.1111/ajt.15096. }\end{array}$ \\
\hline 5 & $\begin{array}{l}\text { Czech } \\
\text { Republic }\end{array}$ & 2016 & In situ & $\begin{array}{l}\text { Clinical pregnancy after deceased donor uterus transplantation: Lessons learned and } \\
\text { future perspectives. } \\
\text { Chmel R, Pastor Z, Novackova M, Matecha J, Cekal M, Fronek J. J Obstet } \\
\text { Gynaecol Res. } 2019 \text { August;45(8):1458-1465. doi:10.1111/jog.13992. }\end{array}$ \\
\hline 6 & Brazil & 2016 & $\begin{array}{l}\text { Birth 2017. Caesarean } \\
\text { hysterectomy }\end{array}$ & $\begin{array}{l}\text { Livebirth after uterus transplantation from a deceased donor in a recipient with } \\
\text { uterine infertility. } \\
\text { Ejzenberg D, Andraus W, Baratelli Carelli Mendes LR, Ducatti L, Song A, } \\
\text { Tanigawa R, Rocha-Santos V, Macedo Arantes R, Soares JM Jr, Serafini PC, } \\
\text { Bertocco de Paiva Haddad L, Pulcinelli Francisco R, Carneiro } \\
\text { D'Albuquerque LA, Chada Baracat E. Lancet. 2019 December } \\
\text { 22;392(10165):2697-2704. doi:10.1016/S0140-6736(18)31766-5. }\end{array}$ \\
\hline 7 & $\begin{array}{l}\text { Czech } \\
\text { Republic }\end{array}$ & 2017 & $\begin{array}{l}\text { Birth } 2019 . \\
\text { Hysterectomy } \\
5 \text { months post-birth }\end{array}$ & $\begin{array}{l}\text { Live Birth Following Uterine Transplantation From a Nulliparous Deceased Donor. } \\
\text { Fronek J, Janousek L, Kristek J, Chlupac J, Pluta M, Novotny R, Maluskova J, } \\
\text { Olausson M. Transplantation. } 2020 \text { June } 9 . \\
\text { doi:10.1097/TP.0000000000003346. }\end{array}$ \\
\hline 8 & $\begin{array}{l}\text { Czech } \\
\text { Republic }\end{array}$ & 2017 & $\begin{array}{l}\text { Hysterectomy month } \\
\text { 7-infection }\end{array}$ & $\begin{array}{l}\text { Revaluation and lessons learned from the first } 9 \text { cases of a Czech uterus } \\
\text { transplantation trial: Four deceased donor and } 5 \text { living donor uterus } \\
\text { transplantations. } \\
\text { Chmel R, Novackova M, Janousek L, Matecha J, Pastor Z, Maluskova J, } \\
\text { Cekal M, Kristek J, Olausson M, Fronek J. Am J Transplant. } 2019 \\
\text { March;19(3):855-864. doi:10.1111/ajt.15096. }\end{array}$ \\
\hline 9 & $\begin{array}{l}\text { USA } \\
\text { (Baylor) }\end{array}$ & 2017 & $\begin{array}{l}\text { Graft failure, failed to } \\
\text { properly reperfuse }\end{array}$ & $\begin{array}{l}\text { The Evolution of Transplantation From Saving Lives to Fertility Treatment: } \\
\text { DUETS (Dallas UtErus Transplant Study). } \\
\text { Testa G, McKenna GJ, Bayer J, Wall A, Fernandez H, Martinez E, Gupta A, } \\
\text { Ruiz R, Onaca N, Gunby RT, Gregg AR, Olausson M, Koon EC, Johannesson } \\
\text { L. Ann Surg. } 2020 \text { July 9. doi:10.1097/SLA.0000000000004199. }\end{array}$ \\
\hline 10 & $\begin{array}{c}\text { USA } \\
\text { (Cleveland) }\end{array}$ & 2017 & $\begin{array}{l}\text { Birth 2019, caesarean } \\
\text { hysterectomy }\end{array}$ & $\begin{array}{l}\text { First birth from a deceased donor uterus in the United States: from severe graft } \\
\text { rejection to successful cesarean delivery. } \\
\text { Flyckt R, Falcone T, Quintini C, Perni U, Eghtesad B, Richards EG, Farrell } \\
\text { RM, Hashimoto K, Miller C, Ricci S, Ferrando CA, D'Amico G, Maikhor S, } \\
\text { Priebe D, Chiesa-Vottero A, Heerema-McKenney A, Mawhorter S, Feldman } \\
\text { MK, Tzakis A. Am J Obstet Gynecol. 2020 August;223(2):143-151. } \\
\text { doi:10.1016/j.ajog.2020.03.001. }\end{array}$ \\
\hline 11 & $\begin{array}{l}\text { Czech } \\
\text { Republic }\end{array}$ & 2018 & Unknown & $\begin{array}{l}\text { Clinical pregnancy after deceased donor uterus transplantation: Lessons learned and } \\
\text { future perspectives. } \\
\text { Chmel R, Pastor Z, Novackova M, Matecha J, Cekal M, Fronek J. J Obstet } \\
\text { Gynaecol Res. } 2019 \text { August;45(8):1458-1465. doi:10.1111/jog.13992. }\end{array}$ \\
\hline 12 & USA (Penn) & 2018 & Birth 2019 & $\begin{array}{l}\text { Live Birth Following Uterine Transplantation From a Nulliparous Deceased Donor. } \\
\text { Fronek J, Janousek L, Kristek J, Chlupac J, Pluta M, Novotny R, Maluskova J, } \\
\text { Olausson M. Transplantation. 2020 June 9. doi:10.1097/TP.0000000000003346. } \\
\text { See also: First Uterus Transplant at Penn Medicine leads to Baby Boy, Penn } \\
\text { Medicine https: / / www.youtube.com/watch?v=BKgr3IFKGzw uploaded } \\
\text { 9th January } 2020 \text { (accessed on 31st January 2021) }\end{array}$ \\
\hline
\end{tabular}




\section{Methods}

In this section, we explain the methods used to establish a database for UTx and how we extracted data for this review. The first author had previously created a database containing data on UTx, clinical trials and births as no such database was publicly available; the second author was involved in updating this database during June and July 2020.

While the full database initially included information from a variety of sources including detailed searches on PubMed, Medline, institutional press releases, and news reports, the database on deceased donation uterus transplantation was recreated to include only information from peer reviewed published sources and clinicaltrials.gov, to ensure accuracy and replicability. To ensure that the database was up to date at the time of writing this article, the search was repeated on clinicaltrials.gov and in PubMed in January 2021 utilising the terms 'uterus transplantation', 'deceased donor', 'uterus transplant'. Ninety-six articles were identified; upon analysis 10 articles were identified that reported on unique deceased donation uterus transplants and births. As it is not possible to get a complete picture from published papers, and that the procedures referred to in media reports might not be published, it is difficult to accurately track progress in UTx; therefore, it is imperative that the recently established international registry for uterus transplantation (IRUTx) collates and publishes public-facing data as soon as possible [10].

Extracted data from the above sources included date and type of donation (live or deceased), method of organ retrieval (open or robotic assisted surgery), recipient details (age and reason for AUFI), donor details (age, parity, relationship to recipient), outcome of recipient surgery (functionality, reasons for removal, episodes of rejection), information regarding births (date of birth, and sex of baby), information on registered clinical trials (date posted on clinicaltrials.gov, recruitment status, inclusion and exclusion criteria), and learning points discussed in published literature. Care was taken to avoid duplicate entries, particularly data on transplants performed. This was achieved by cross-referencing patient and donor details across publications where similar data were found.

Once complete, the data contained within the database were reviewed and analysed. As of the 31st January 2021, the authors had identified references in published sources to twelve deceased donation uterus transplants and five births.

This article reports on DD UTx using peer reviewed literature published in academic journals; whilst the data may be incomplete due to this limitation, the review is still of benefit and value to the field of UTx. Ethics approval was not required for the creation of the database as sources were publicly available.

\section{Results}

In this section, the results of the review including recent developments in the field, graft survival, rejection episodes, nulliparous donors, cold ischaemic time and problems in pregnancy are discussed.

In 2012, a team in Sweden was the first in the world to start a UTx clinical trial; this first trial focussed solely on utilising live donor transplants. Since the first birth achieved by the Swedish team in 2014 [4], the interest in, and number of clinical trials in, both LD and DD UTx have greatly increased. Trials are currently happening, or are planned, in Belgium, Brazil, Czech Republic, Egypt, France, Germany, Spain, Sweden, the United Kingdom and the United States of America (listed on clinicaltrials.gov, accessed 31st January 2021).

The first DD clinical trial on clinicaltrials. gov was proposed by Womb Transplant UK in March 2015. As of 31st January 2021, there were 8 DD UTx trials listed on clinicaltrials.gov. Of these, one had been withdrawn due to lack of funding (Nebraska, USA), and one was an observational study (UK). Of the remaining seven trials, four were actively recruiting (Belgium, UK, Pennsylvania and Cleveland, USA), one was enrolling by invitation (Sweden), one was not yet recruiting (Boston, USA), and one was unknown although likely to be recruiting due to links with the observational study (UK). It should also be noted that further clinical trials have taken place in Brazil, Lebanon, China and India, although these were not listed on clinicaltrials.gov at the time of writing [21,22]. 
The Institute of Clinical and Experimental Medicine (IKEM) in the Czech Republic and Baylor University Medical Institute, USA, are conducting trials that include both LD and DD, the Swedish team has approval for multiple trials that include either LD or DD, and the UK team have also announced the expansion of their trial to include both DD and LD [23]. Although the secondary outcomes measures are undeclared for Baylor Institute on clincialtrials.gov, IKEM aims to compare the efficacy of LD vs DD UTx. This makes these trials unique since few institutes are able to compare data from both donor types in one setting [24].

Since the first DD UTx in Turkey in 2011, 11 more DD UTx have been performed in the USA, Czech Republic, and Brazil. The Cleveland Clinic, USA, performed the second deceased donor UTx in 2016 [25]. In the same year, deceased donations were performed by the Czech Republic [13] and Brazil [5] with interest and successes steadily growing.

To date, five births from DD UTx have been reported in the literature. In December 2017, the first livebirth was achieved by a team at the University of São Paolo, Brazil, and provided proof of concept that a transplanted uterus from a deceased donor could successfully carry a foetus to birth [5]. The second live birth occurred at the Cleveland Clinic, USA, in 2019 [6] and was followed by IKEM, Czech Republic [8]; Penn Medicine, USA [8,26]; and Baylor, USA [7].

Table 2 provides a summary of DD UTx: the order by date of the procedures, the country where the DD UTx was performed, year of UTx, the outcome and the published literature.

\subsection{Failed Graft Survival}

Uterine graft survival for more than 3 months defines surgical success [24]. Of the 12 DD UTx performed, 9 (75\%) achieved surgical success. Thrombosis of the uterine vessels is a frequent reason for recipients' hysterectomy following both live and deceased donation $[3,13,27,28]$. One case of thrombosis has been reported, discovered by routine doppler ultrasound and cervical examination; laparotomy and subsequent hysterectomy were performed due to necrosis of the graft 7 days post-operatively [13]. Failure to perfuse despite patency of the vasculature was another reported reason for graft loss [29]. Another hysterectomy was performed on day 12 post-operatively due to bleeding caused by a vascular candidal infection, which disrupted the blood supply to the graft [25]. Finally, it is noted that despite surgical success, one graft failed and was removed 7 months postoperatively due to infection by Herpes Simplex Virus-2 (HSV-2). This presented with failure to menstruate three months post-operatively, no endometrium on ultrasound and cervical canal stenosis [13]. As such 8 of the 12 (66.7\%) reported cases of DD UTx have progressed to the embryo transfer stage.

\subsection{Rejection Episodes}

Graft rejection ranges from mild to severe and can be medically treated, as opposed to graft loss described above. Episodes of graft rejection are frequently reported in LD and DD, and this is an area requiring further research in order to improve outcomes of UTx [30]. Two cases of graft rejection in DD UTx have been published [6,8]. In DD UTx, rejection has been reported to present symptomatically (with increased abnormal vaginal discharge) or asymptomatically. All episodes of rejection experienced by IKEM were clinically silent, emphasising the importance of regular cervical biopsy after transplantation and during early pregnancy. Despite severe rejection episodes, however, livebirth can still be achieved $[6,8]$.

\subsection{Nulliparous Donors}

The obstetric success and desirability of live and deceased nulliparous donors is debated in the literature [31,32]. This is a more prominent problem in deceased donation as live donations are often from parous donors, often the recipient's mother. Unproven fertility was thought to impact obstetrical success when the first recipient of a nulliparous DD uterus 
experienced recurrent failed embryo transfer (ET) and miscarriages [33]. With recipients undertaking extensive, invasive procedures in order to gestate, researchers understandably wish to utilise uteri that have already proven their ability to gestate successfully, and to increase success rates. Transplanting a graft which potentially is unable to sustain a foetus to full term may not, at first sight, appear desirable. However, recent research demonstrates that excluding nulliparous DD as well as DD who have experienced a miscarriage may exclude a significant proportion of potential donors, reducing further the potential pool of donors; the likelihood is small of a normal uterus not functioning [32]. Indeed, a livebirth from a nulliparous donor has been reported [8]. We have proof of concept that a nulliparous deceased donor UTx can result in a livebirth, and perhaps the uncertainty of the success of nulliparous donors has been overvalued [5].

\subsection{Cold Ischaemic Time}

Cold ischaemic time (CIT) is thought to affect the functionality of the graft in the short and long term [34]. The viability and functionality of the uterus after prolonged ischaemia has been frequently discussed in published literature. Animal studies show that uteri have good tolerance to an extended period of cold ischaemia, up to $24 \mathrm{~h}$ [34], but this is yet to be thoroughly investigated in human studies. Although a shorter CIT of 1 hour 50 minutes is achievable [6] and resulted in a livebirth, longer CITs of 6 hours 20 minutes [5] and 9 hours 9 minutes [8] did not appear to affect graft functionality as both achieved livebirths. Previously, the uterus was the last procured organ due to the non-lifesaving and experimental nature of the concept [35]. This has been suggested to be the reason for the prolonged CIT [5]. Reordering the procurement of organs from the donor [35], having the recipient in close proximity to the donor, timing of recipient surgery [6] and novel surgical techniques (discussion of which is beyond the scope of this article) have been shown to reduce CIT. Further research into this area should improve DD transplantation success [36]. In addition, it must be noted that uteri from those donating after circulatory death (DCD) is not currently recommended, as the impact of a prolonged warm ischaemia time on the reproductive function is unknown; however, this is an aspect of DD UTx that is worthy of further research [32].

\subsection{Problems in Pregnancy}

Details of four out of the five reported DD UTx births have been published. Obstetric complications from these include pre-eclampsia [13], placenta accreta [6] and gestational diabetes [8]. It is reported that the Brazilian UTx recipient did not experience any obstetric problems [5]. At the time of writing, details relating to the birth at Penn Medicine are yet to be published.

It has been suggested that the cause of pre-eclampsia in births after LD UTx was due to stiffer and less elastic arteries from older donors [13]. As suitable DD are on average younger than live donors, this could provide a medical justification for preferring DD over LD.

Evidence shows that pregnancies after solid organ transplants (SOT) (including kidneys and liver transplants) increases the risk of obstetric complications such as preeclampsia and preterm birth when compared to non-transplanted pregnancies [19]. Furthermore, pregnancies conceived through in vitro fertilisation (IVF) have increased risk of obstetric complications. The accumulative risk of SOT with IVF suggests that the risks for the mother are much higher than for spontaneous conception without transplant [19]. However, due to the small numbers of DD UTx procedures and outcomes reported, it is difficult to make clear comparisons at this stage; further work will strengthen the research base.

\section{Discussion}

As there is currently limited data available, it is difficult to draw clear comparisons between LD and DD UTx. However, the selection criteria for DD must be kept under 
review, particularly any restrictions that limit UTx to DD who are parous. Researchers prefer younger uterus donors due to risks of vasculature disorders in women over age 65, an issue which has been highlighted in LD trials where older donors (often recipient's mothers) are frequently used [37]. With a preference for younger donors, there is a significant chance that a DD will be nulliparous; if such donors were automatically excluded from uterus donation, this would further shrink the potential pool of DD. With DD ethically preferable to $\mathrm{LD}$, and with proof of concept shown, it would not be reasonable to exclude nulliparous DD from UTx at this stage in research.

Furthermore, all the births (including live and deceased) for which complete data are available were preterm births (defined as birth before 37 weeks' gestation per World Health Organisation definitions) $[19,38]$. While early births via caesarean section are planned for all UTx births, many (including LD UTx) have occurred earlier than planned. Due to a lack of information and the limited numbers from which to draw firm conclusions, the reasons are currently unclear. The lack of published data from long-term studies into the health of the children specifically born from transplanted uteri means that we are currently unable to assess the impact of pre-term birth; however, it is known that preterm babies are at higher risk of neurodevelopmental, respiratory and behavioural problems [19,38].

There is currently insufficient evidence to compare the obstetric outcomes between LD and DD transplants, making it difficult to use this to justify the use of deceased donors over live donors. As such, the continuance of trials with both LD and DD are justified, until further data are available that may prove conclusive.

Once UTx trials are complete, it may be that the use of LD will be both medically and ethically justified. However, as noted by Williams, should there "be both no shortage of DD uteri and the use of LD is no more likely/only slightly more likely to prove successful, [it may be claimed] that LD should not be utilized" [11]. It must be recognised that there is limited availability of deceased uterus donors; one recent review approximated a maximum number of 2.33 potential donors per million people [31]. Whilst there may be limited availability, DD UTx is desirable as it avoids the ethical and medical risks associated with LD. Equally, it must not be assumed that DD UTx will automatically be covered by organ donation systems that presume consent upon death; rather, specific consent for uteri donation after death must be sought and established (either from the donor pre-death or from another authorised person such as a family member) [39].

The financial costs of DD UTx may also demonstrate another reason for preferring DD UTx over LD UTx. However, comparisons are currently difficult to make accurately, as only details of the costs of LD UTx have been published [40].

Long-term studies of the UTx recipients and outcomes (including long-term studies of children born following UTx) have significant value; it is desirous that all uterus transplants and outcomes are centrally recorded, to enable, facilitate, collate and publish the results of UTx procedures and long-term studies. The potential benefits of the recently established international registry for uterus transplantation (IRUTx) are clear [10]. In addition, further studies are needed to review the safety and efficacy of DD UTx as compared to LD UTx. Due to wider searches involving press releases and news reports, the authors are aware of further DD UTx procedures and births; however, these have not been reported in the literature. This further demonstrates the need of the IRUTx to collate and publish information on this novel reproductive transplant technology.

\section{Conclusions}

The first live births following DD UTx demonstrate that DD is a viable donor option for UTx. Research into DD UTx is continuing apace worldwide, and it is predicted that further births will happen in the near future. Currently, there are insufficient data to determine if either deceased or living donor models for UTx should be preferred on medical grounds, or if both offer a viable treatment option, and long-term follow up of recipients and any children born is required to establish this. As such, it is recommended that for the time being both LD and DD UTx trials continue, with constant review of cases and outcomes. 
Current and future research will continue to establish appropriate medical procedures for both retrieval and implantation, as well as outcomes for DD UTx. The international registry for uterus transplantation (IRUTx) is vital for this ongoing research and follow up studies and can make a vital contribution to the field of UTx. The ethical advantages of DD UTx, alongside the medical advances made, demonstrates promising outcomes for this innovative field of reproductive transplantation.

Author Contributions: Conceptualization, N.H.-B.; Methodology, N.H.-B. and S.L.Y.; Formal Analysis, N.H.-B. and S.L.Y.; Supervision, N.H.-B.; Writing-original draft, N.H.-B. and S.L.Y.; Writingreview and editing, N.H.-B. and S.L.Y.; Funding Acquisition, N.H.-B. All authors have read and agreed to the published version of the manuscript.

Funding: This research received no external funding. Internal funding was received from the School of Law and Politics Research Support Scheme, Cardiff University (awarded 2020).

Institutional Review Board Statement: Ethical review and approval were not applicable.

Informed Consent Statement: Not applicable, the research did not involve humans.

Data Availability Statement: Data supporting findings are in the published sources as detailed in Table 2 and the bibliography.

Acknowledgments: Natasha Hammond-Browning would like to thank the members of her Coffee, Research and Pastries Group for their time and effort in reviewing and commenting on drafts of this paper, and to N J Williams for comments on a draft of this paper.

Conflicts of Interest: The authors declare no conflict of interests. The internal funding body had no role in the design, execution, interpretation, or writing of the study.

\section{References}

1. Eraslan, S.; Hamernik, R.J.; Hardy, J.D. Replantation of Uterus and Ovaries in Dogs, with Successful Pregnancy. Arch. Surg. 1966, 92, 9-12. [CrossRef] [PubMed]

2. Jones, B.P.K.L.; Vali, S.; Saso, S.; Jalmbrant, M.; Bracewell-Milnes, T.; Thum, M.-Y.; Quiroga, I.; Friend, P.; Diaz-Garcia, C.; Ghaem-Maghami, S.; et al. Uterine Transplantation; Review of Livebriths and Reproductive Implications. Transplantation 2021. [CrossRef]

3. Fageeh, W.; Raffa, H.; Jabbad, H.; Marzouki, A. Transplantation of the human uterus. Int. J. Gynecol. Obstet. 2002, 76, $245-251$. [CrossRef]

4. Brännström, M.; Johannesson, L.; Bokström, H.; Kvarnström, N.; Mölne, J.; Dahm-Kähler, P.; Anders Enskog, M.M.; Jana Ekber; Diaz-Garcia, C.; Gäbel, M.; et al. Livebirth after uterus transplantation. Lancet 2015, 385, 607-616. [CrossRef]

5. Ejzenberg, D.; Andraus, W.; Mendes, L.R.B.C.; Ducatti, L.; Song, A.; Tanigawa, R.; Rocha-Santos, V.; Arantes, R.M.; Soares, J.M.; Serafini, P.C.; et al. Livebirth after uterus transplantation from a deceased donor in a recipient with uterine infertility. Lancet 2018, 392, 2697-2704. [CrossRef]

6. Flyckt, R.; Falcone, T.; Quintini, C.; Perni, U.; Eghtesad, B.; Richards, E.G.; Farrell, R.M.; Hashimoto, K.; Miller, C.; Ricci, S.; et al. First birth from a deceased donor uterus in the United States: From severe graft rejection to successful cesarean delivery. Am. J. Obstet. Gynecol. 2020, 223, 143-151. [CrossRef] [PubMed]

7. Johannesson, L.; Testa, G.; Putman, J.M.; McKenna, G.J.; Koon, E.C.; York, J.R.; Bayer, J.; Zhang, L.; Rubeo, Z.S.; Gunby, R.T.; et al. Twelve Live Births After Uterus Transplantation in the Dallas UtErus Transplant Study. Obstet. Gynecol. 2021, 137, 241-249. [CrossRef]

8. Fronek, J.; Janousek, L.; Kristek, J.; Chlupac, J.; Pluta, M.; Novotny, R.; Maluskova, J.; Olausson, M. Live Birth Following Uterine Transplantation from a Nulliparous Deceased Donor. Transplantation 2020. [CrossRef] [PubMed]

9. Brannstrom, M. Pioneer in Uterus Transplantation. Transplantation 2020, 104, 1117-1118.

10. Hammond-Browning, N.; Williams, N.J. Developing an International Registry for Uterus Transplantation (IRUTx): Promises and Challenges. Hum. Reprod. 2020, 35, 2643-2649. [CrossRef]

11. Williams, N. Should Deceased Donation be Morally Preferred in Uterine Transplantation Trials? Bioethics 2016, 30, $415-424$. [CrossRef] [PubMed]

12. Bruno, B.; Arora, K.S. Uterus Transplantation: The Ethics of Using Deceased Versus Living Donors. Am. J. Bioeth. 2018, 18, 6-15. [CrossRef]

13. Chmel, R.; Novackova, M.; Janousek, L.; Matecha, J.; Pastor, Z.; Maluskova, J.; Cekal, M.; Kristek, J.; Olausson, M.; Fronek, J. Revaluation and lessons learned from the first 9 cases of a Czech uterus transplantation trial: Four deceased donor and 5 living donor uterus transplantations. Arab. Archaeol. Epigr. 2019, 19, 855-864. [CrossRef] [PubMed] 
14. Kisu, I.; Mihara, M.; Banno, K.; Umene, K.; Araki, J.; Hara, H.; Suganuma, N.; Aoki, D. Risks for Donors in Uterus Transplantation. Reprod. Sci. 2013, 20, 1406-1415. [CrossRef] [PubMed]

15. Ricci, S.; Bennett, C.; Falcone, T. Uterine Transplantation: Evolving Data, Success, and Clinical Importance. J. Minim Invasive Gynecol. 2021, 28, 502-512. [CrossRef] [PubMed]

16. Gameiro, S. Straight out of the womb: The psychsocial implications of uterine transplants. Fertil. Steril. 2020, 114, 285-286. [CrossRef] [PubMed]

17. Chmel, R.; Pastor, Z.; Novackova, M.; Matecha, J.; Cekal, M.; Fronek, J. Clinical pregnancy after deceased donor uterus transplantation: Lessons learned and future perspectives. J. Obstet. Gynaecol. Res. 2019, 45, 1458-1465. [CrossRef] [PubMed]

18. Jones, B.P.; Saso, S.; Bracewell-Milnes, T.; Thum, M.-Y.; Nicopoullos, J.; Diaz-Garcia, C.; Friend, P.; Ghaem-Maghami, S.; Testa, G.; Johannesson, L.; et al. Human uterine transplantation: A review ofoutcomes from the first 45 cases. BJOG 2019, 126, 1310-1319. [CrossRef] [PubMed]

19. Daolio, J.; Palomba, S.; Paganelli, S.; Falbo, A.; Aguzzoli, L. Uterine transplantation and IVF for congenital or acquired uterine factor infertility: A systematic review of safety and efficacy outcomes in the first 52 recipients. PLoS ONE 2020, 15, e0232323. [CrossRef]

20. Flyckt, R.L.; Farrell, R.M.; Perni, U.C.; Tzakis, A.G.; Falcone, T. Deceased Donor Uterine Transplantation: Innovation and Adaptation. Obstet Gynecol. 2016, 128, 837-842. [CrossRef]

21. 1st Congress of ISUTx 2017; Gothenburg, Sweden. Available online: https://www.isutx.org/congress-2017/ (accessed on 29 September 2020).

22. 1st State-of-the-Art Meeting of ISUTx2018; Ghent, Belgium. Available online: https://www.isutx.org/1st-state-of-the-artmeeting-of-isutx/ (accessed on 29 September 2020).

23. WTUK. The UK Womb Transplant Research Team to Expand Research Programme. 2018. Available online: http:/ / wombtransplantuk. org/the-uk-womb-transplant-research-team-to-expand-research-programme (accessed on 29 September 2020).

24. Chmel, R.; Pastor, Z.; Matecha, J.; Janousek, L.; Novackova, M.; Fronek, J. Uterine transplantation in an era of successful childbirths from living and deceased donor uteri: Current challenges. Biomed. Pap. 2020, 164, 115-120. [CrossRef] [PubMed]

25. Flyckt, R.; Kotlyar, A.; Arian, S.; Eghtesad, B.; Falcone, T.; Tzakis, A. Deceased donor uterine transplantation. Fertil. Steril. 2017, 107, e13. [CrossRef] [PubMed]

26. Howard, J. Second Baby in the US Born from Transplanted Uterus of Deceased Donor. 2020. Available online: https:/ / edition. cnn.com/2020/01/09/health/uterus-transplant-second-birth-us-bn/index.html (accessed on 29 September 2020).

27. Brännström, M.; Johannesson, L.; Dahm-Kähler, P.; Enskog, A.; Mölne, J.; Kvarnström, N.; Diaz-Garcia, C.; Hanafy, A.; Lundmark, C.; Marcickiewicz, J.; et al. First clinical uterus transplantation trial: A six-month report. Fertil. Steril. 2014, 101, 1228-1236. [CrossRef]

28. Testa, G.; Koon, E.C.; Johannesson, L.; McKenna, G.J.; Anthony, T.; Klintmalm, G.B.; Gunby, R.T.; Warren, A.M.; Putman, J.M.; de Prisco, G.; et al. Living Donor Uterus Transplantation: A Single Center's Observations and Lessons Learned from Early Setbacks to Technical Success. Am. J. Transplant. 2017, 17, 2901-2910. [CrossRef] [PubMed]

29. Testa, G.; McKenna, G.J.; Bayer, J.; Wall, A.; Fernandez, H.; Martinez, E.; Amar, G.; Richard, R.; Nicholas, O.; Gunby, R.T.; et al. The Evolution of Transplantation from Saving Lives to Fertility Treatment: DUETS (Dallas UtErus Transplant Study). Ann. Surg. 2020, 272, 411-417. [CrossRef] [PubMed]

30. Tummers, P.; Göker, M.; Dahm-Kahler, P.; Brännström, M.; Tullius, S.G.; Rogiers, X.; Van Laecke, S.; Weyers, S. Meeting Report: First State-of-the-Art Meeting on Uterus Transplantation. Transplantation 2019, 103, 455-458. [CrossRef] [PubMed]

31. Kristek, J.; Johannesson, L.; Testa, G.; Chmel, R.; Olausson, M.; Kvarnström, N.; Karydis, N.; Fronek, J. Limited Availability of Deceased Uterus Donors: A Transatlantic Perspective. Transplantation 2019, 103, 2449-2452. [CrossRef]

32. Jones, B.P.; Saso, S.; Quiroga, I.; Yazbek, J.; Smith, J.R. Limited Availability of Deceased Uterus Donors: A UK Perspective. Transplantation 2020, 104, e250-e251. [CrossRef]

33. Ozkan, O.; Dogan, N.U.; Ozkan, O.; Mendilcioglu, I.; Dogan, S.; Aydinuraz, B.; Simsek, M. Uterus transplantation: From animal models through the first heart beating pregnancy to the first human live birth. Women's Health 2016, 12, 442-449. [CrossRef]

34. Tardieu, A.; Dion, L.; Lavoué, V.; Chazelas, P.; Marquet, P.; Piver, P.; Sallée, C.; Aubard, Y.; Guellec, C.B.-L.; Favreau, F.; et al. The Key Role of Warm and Cold Ischemia in Uterus Transplantation: A Review. J. Clin. Med. 2019, 8, 760. [CrossRef] [PubMed]

35. Testa, G.; Anthony, T.; McKenna, G.J.; Koon, E.C.; Wallis, K.; Klintmalm, G.B.; Reese, J.C.; Johannesson, L. Deceased donor uterus retrieval: A novel technique and workflow. Arab. Archaeol. Epigr. 2017, 18, 679-683. [CrossRef]

36. Flyckt, R.; Farrell, R.; Falcone, T.; Tullius, S.G.; Brännström, M.; Dahm-Kähler, P.; Tzakis, A. Meeting Report: Second World Congress of the International Society of Uterus Transplantation, Cleveland. Transplantation 2020, 104, 1312-1315. [CrossRef]

37. Dion, L.; Tardieu, A.; Garbin, O.; Ayoubi, J.M.; Agostini, A.; Collinet, P.; Yves, A.; Pascal, P.; Tristan, G.; Lavoué, V. Should brain-dead or living donors be used for uterus transplantation? A statement by the CNGOF French Uterus Transplantation Committee (CETUF). J. Gynecol. Obstet. Hum. Reprod. 2019, 48, 9-10. [CrossRef] [PubMed]

38. Platt, M. Outcomes in preterm infants. Public Health 2014, 128, 399-403. [CrossRef] [PubMed]

39. Williams, N.J. Deceased Donation in Uterus Transplantation Trials: Novelty, Consent, and Surrogate Decision Making. Am. J. Bioeth. 2018, 18, 18-20. [CrossRef] [PubMed]

40. Davidson, T.; Ekberg, J.; Sandman, L.; Brännström, M. The costs of human uterus transplantation: A study based on the nine cases of the initial Swedish live donor trial. Hum. Reprod. 2021, 36, 358-366. [CrossRef] [PubMed] 